\title{
The relative importance of different types of rewards for employee motivation and commitment in South Africa
}

\author{
Authors: \\ Aleeshah Nujjoo ${ }^{1}$ \\ Ines Meyer ${ }^{1}$ \\ Affiliations: \\ ${ }^{1}$ Organisational Psychology \\ Section, School of \\ Management Studies, \\ University of Cape Town, \\ South Africa \\ Correspondence to: \\ Ines Meyer \\ Email: \\ ines.meyer@uct.ac.za \\ Postal address: \\ School of Management \\ Studies, University of \\ Cape Town, Private Bag, \\ Rondebosch 7700 \\ South Africa \\ Dates: \\ Received: 28 Oct. 2011 \\ Accepted: 26 Sept. 2012 \\ Published: 26 Nov. 2012 \\ How to cite this article: \\ Nujjoo, A., \& Meyer, \\ I. (2012). The relative \\ importance of different types \\ of rewards for employee \\ motivation and commitment \\ in South Africa. SA Journal \\ of Human Resource \\ Management/SA Tydskrif vir \\ Menslikehulpbronbestuur, \\ 10(2), Art. \#442, 10 pages. \\ http://dx.doi.org/10.4102/ \\ sajhrm.v10i2.442
}

C) 2012. The Authors. Licensee: AOSIS OpenJournals. This work is licensed under the Creative Commons Attribution License.
Orientation: Employees' perceptions of rewards are related to their affective commitment and intrinsic motivation, which have been associated with staff turnover.

Research purpose: The study sought to establish the relationship between intrinsic and different extrinsic rewards with intrinsic motivation and affective commitment.

Motivation for the study: South African organisations are grappling with employee retention. Literature shows that employees who are more motivated and committed to their organisation are less likely to quit. Rewards management strategies serve to create a motivated and committed workforce. Using the correct types of rewards can thus provide a competitive advantage.

Research design, approach and method: A cross-sectional, correlational study was conducted. Questionnaire data of 399 South African employees were analysed using bivariate correlations and multiple regression.

Main findings: Three main findings emerged. Firstly, there is a relationship between all types of rewards investigated and the two outcome variables. Secondly, this relationship is stronger for intrinsic than for extrinsic rewards and thirdly, monetary rewards do not account for the variance in intrinsic motivation above that of non-monetary rewards.

Practical/managerial implications: Rewards management strategies should focus on job characteristics and designs to increase staff intrinsic rewards and include non-monetary rewards, such as supportive leadership, to encourage employees' intrinsic motivation and affective commitment.

Contribution/value-add: This research demonstrated the important role different rewards, particularly intrinsic non-monetary rewards, play in creating a committed and motivated workforce. The insights gained from this study can promote organisational effectiveness. Suggestions of how to expand on and refine the current study are addressed.

\section{Introduction}

\section{Problem statement}

\section{Key focus of the study}

As a consequence of competitive markets, technological advancements and globalisation, organisations worldwide are facing challenges in retaining their human capital. This is no different in South Africa, as research by Kinnear and Sutherland (2001) has shown. Staff attrition is of concern to organisations because of its high associated cost. It is estimated that the total cost of an exempted employee turnover amounts to a minimum of one year's pay and benefits (Ramlall, 2004). In addition to the direct costs, the exit of employees also implies the loss of valuable intellectual capital and thus competitive advantage. In order to retain its staff, organisations often focus on remuneration and other monetary benefits as their main retention strategy although research has long established that employees are unlikely to remain in the employment relationship when incentivised by monetary benefits alone (e.g. Herzberg, 1959). This begs the question as to what other types of rewards could be effective in reducing the risk of staff turnover in South African organisations through their relationship with affective commitment and motivation.

\section{Background to the study, research purpose and trends from research literature}

Rewards management is one of the key strategies used to create a motivated and committed workforce. Studies have long shown that employees who are motivated and committed to the organisation are less likely to quit (Mowday, 1998; Ramlall, 2004). Favourable perceptions of rewards, in turn, have been linked to positive human resource outcomes such as employee 
job satisfaction, work motivation, affective commitment, high levels of performance and organisational effectiveness (Bratton \& Gold, 2007; Squires, 2001; Ulrich, 1997). The influence of effective rewards management on employees' affective commitment, motivation and subsequent high organisational performance is clearly reflected in practice examples. Google, for instance, is currently ranked 4th in Fortune's Top 10 Best Companies to Work For, branding it as one of the most desirable employers worldwide (CNN Money, 2011). Company reports indicate a high rate of employee satisfaction, low employee turnover and high organisational profitability. Google's employee management and retention strategies incorporate both monetary and nonmonetary rewards. On average, Google employees receive a salary of $£ 86800$ a year, as compared to an average of $£ 21500$ in the UK private sector (Rupert, 2011). Furthermore, in line with changing work patterns, Google's reward management strategy includes flexi-time and a work environment that reconciles employees' work-life balance. Google employees are also encouraged to spend $70 \%$ of their time on core business tasks, $20 \%$ on projects related to the core business and $10 \%$ on any pet projects unrelated to the core business (The Google Culture, 2011). This serves to boost employees' competitive intrinsic motivation, as well as rewards and job satisfaction. Google's strategy thus follows Perkins' (1988) suggestion that individuals who are intrinsically motivated seek opportunities to solve boundary-pushing challenges, demonstrate high levels of commitment to their organisation and are thus less likely to leave the employment relationship.

\section{Objectives}

This study seeks to explore what types of rewards South African organisations could include in retention strategies to make these strategies work most effectively. To this purpose it draws on a sample of South African employees to investigate the relative importance of employee satisfaction with different types of rewards in predicting two factors that make it likely for employees to remain in the employment relationship, namely, intrinsic motivation and affective commitment.

\section{Contribution to the field}

Whilst there is high workforce mobility throughout the world, retaining employees in South Africa is particularly challenging because large numbers of skilled employees leave the country. South African organisations should thus be particularly concerned about finding rewards strategies that are valued by their employees. Yet, whilst the literature reviewed in this article shows that elsewhere in the world, particularly in the United States, studies linking different types of rewards to employee motivation and affective commitment peaked from the late 1980s to early 2000s, there is a scarcity of such research in South Africa. It is thus likely that South African organisations have chosen to adopt reward management strategies that have been found effective in other countries without considering that management principles might not apply in a cultural context different to the one in which they were developed (Greenberg, 2011;
Huang \& Van de Vliert, 2003). The study described in this article thus closes an important gap by investigating the views from a diverse sample of South African employees working across a wide variety of sectors and employment levels. By revealing which reward strategies are most closely linked to employee motivation and affective commitment, it contributes to assisting organisations in determining which rewards management strategies to focus on in order to increase staff retention and thus organisational effectiveness.

\section{What will follow}

The following literature review develops a classification of different types of rewards which forms the framework for the empirical analyses in this study. It also outlines the empirical relationships found between these rewards and affective commitment as well as intrinsic motivation. Following this, the method used in this study is outlined and the results described. The article closes with a discussion of these results including their practical implications.

\section{Literature review}

\section{Definition of rewards}

Monetary rewards are legal obligations in the employment relationship and are critical incentives to attract and retain employees. However, the relevant literature indicates that rewards transcend monetary boundaries and several reward categorisations have been proposed (Chen, Ford \& Farris, 1999; Katz \& Van Maanen, 1977; Malhotra, Budhwar \& Prowse, 2007; Weatherly, 2002). A classic categorisation by Porter and Lawler (1968) distinguishes between intrinsic and extrinsic rewards. Porter and Lawler defined intrinsic rewards as the satisfaction that a person derives from doing the job and extrinsic rewards as tangible benefits obtained as a result of doing the job, such as pay and promotions. Mottaz (1985), on the other hand, differentiated between task, social and organisational rewards. Task rewards are intrinsic by nature and refer to the inherent aspects of an employee's duties such as the responsibility and autonomy he or she is given in completing a task and the importance of the task for the overall organisation. Conversely, social and organisational rewards are extrinsic rewards. Social rewards refer to nonjob related factors such as the interpersonal relationships with colleagues and supervisory support. Organisational rewards appertain to visible rewards provided by the organisation such as pay, bonuses and fringe benefits (Katz \& Van Maanen, 1977; Malhotra et al., 2007; Mottaz, 1985). Rewards have also been classified as either monetary or nonmonetary. Monetary rewards refer to tangible objects, such as pay, bonuses, promotions and formal recognitions, whilst non-monetary rewards are non-tangible and include praise and personal recognitions (Weatherly, 2002). Chen et al. (1999) and Weatherly (2002) argue that monetary, as well as some non-monetary rewards, can be considered extrinsic rewards.

In this paper a reward taxonomy is used that merges the frameworks presented by Chen et al. (1999) and Mottaz (1985). Whilst Porter and Lawler (1968) present a simplistic 
model that only distinguishes between intrinsic and extrinsic rewards, both Chen et al. and Mottaz, consider a more differentiated view. The model presented in this paper considers the task, social and organisational dimensions as well as the intrinsic, extrinsic, monetary and non-monetary nature of rewards. Rewards are categorised as intrinsic nonmonetary (INMR), extrinsic non-monetary (ENMR) and extrinsic monetary (EMR) (Figure 1).

Intrinsic non-monetary rewards refer to rewards that are inherent to the nature of the job. Intrinsic non-monetary rewards can thus be seen as the positive emotional gratifications that an individual gets from his or her efforts at work (Porter \& Lawler, 1968). They can thus be equated to what Kallerberg (1977) termed intrinsic job satisfaction. For this reason the terms intrinsic job satisfaction and intrinsic non-monetary rewards are used interchangeably in this study. Intrinsic job satisfaction has been related to several occupational and organisational outcomes such as motivation, affective commitment, retention and organisational effectiveness (Kallerberg, 1977; Selden \& Brewer, 2000).

Extrinsic non-monetary rewards refer to external social rewards with respect to the job, such as healthy relationships with colleagues, supervisory support and their verbal praise (Katz \& Van Maanen, 1977; Malhotra et al., 2007; Mottaz, 1985). This particular study will focus on employees' perceptions of supervisory support. Studies have provided empirical evidence that perceptions of supervisory support positively affect employees' motivation and affective commitment towards the organisation (Eisenberger, Stinglhamber, Vandenberghe, Sucharski \& Rhoades, 2002; Randall \& O'Driscoll, 1997; Williams, Brower, Ford, Williams \& Carraher, 2008). In this study, ENMRs are understood in line with Gagnon and Michael's (2004) definition of perceived supervisory support which is 'the degree to which employees feel that they are supported by their supervisor' (p. 173). Extrinsic non-monetary rewards may involve taskoriented and socio-emotional actions such as communication, goal-setting, provision of constructive feedback, showing understanding and expressing concern (Amabile, Schatzel, Moneta \& Kramer, 2004).

Extrinsic monetary rewards, as defined in this study, represent organisational rewards such as pay, bonuses, security, formal recognitions and awards and fringe benefits including travel (Chen et al., 1999; Malhotra et al., 2007; Mottaz, 1985; Weatherly, 2002).

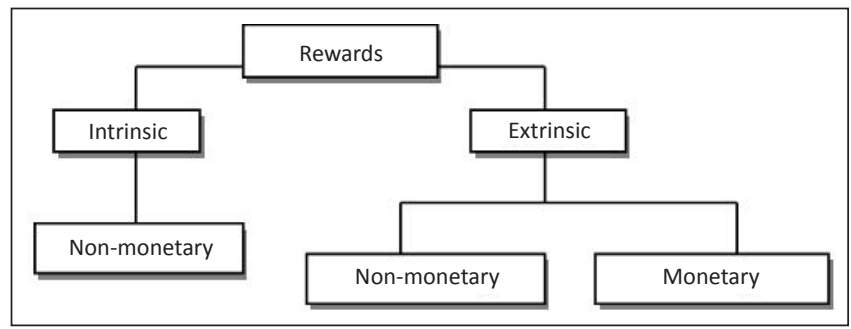

FIGURE 1: Taxonomy of different types of intrinsic and extrinsic rewards offered by companies used in this study.

\section{Rewards and affective commitment}

Organisational commitment can be categorised into normative, continuance and affective commitment (Meyer \& Allen, 1997). Normative commitment refers to employees' perceived obligation to stay with an organisation whilst employees with continuance commitment choose to stay with an organisation because they have no choice (Malhotra et al., 2007; Meyer \& Allen, 1991). In contrast, affective commitment is conceptualised as an emotional attachment and loyalty displayed towards the organisation as a result of rewards obtained (Kuvaas, 2006; Malhotra et al., 2007). Affective commitment is the commitment dimension which has been found to be most strongly related to positive occupational and organisational outcomes such as job satisfaction, motivation and employee retention (Buitendach \& De Witte, 2005). In line with Malhotra et al.'s (2007) definition, this paper defines affective commitment as an employee's emotional attachment, identification and involvement with the organisation as a result of favourable perceptions of tangible and non-tangible benefits.

Generally, positive relationships have been found between affective commitment and rewards (Burke, 2002; Kuvaas, 2006; Malhotra et al., 2007). Malhotra et al. (2007) explain this relationship in terms of an act of reciprocity, according to which employees enter organisations with the expectation of being given the right platform to use their skills and to satisfy their needs and desires. Malhotra et al. further claim that when an organisation fulfils employees' monetary and non-monetary expectations, their affective commitment increases. Whilst Kuvaas (2006) found that pay and bonuses contribute to employees' affective commitment, Malhotra et al. (2007) established that intrinsic non-monetary rewards are more powerful predictors of affective commitment than monetary rewards (see also Eby, Freeman, Rush \& Lance, 1999; O’Reilly \& Caldwell, 1980).

Furthermore, social rewards (i.e. ENMRs), help employees develop trust and interest in pursuing organisational goals (Burke, 2002). Adeyemo and Aremu (1999), for example, found that employees who perceived their supervisor as supportive were more affectively committed to their employer. Burke (2002) argues that when supervisors are committed to their subordinates and engage in behaviours that support organisational objectives, employees experience emotional gratification and are more likely to respond by developing trust and modelling their supervisor's behaviours. Based on the above arguments and empirical findings, the following hypotheses have been derived:

- Hypothesis 1: Employees show higher affective commitment to their employer the more favourably they perceive the intrinsic non-monetary rewards, extrinsic non-monetary rewards and extrinsic monetary rewards provided.

- Hypothesis 2: Employees' favourable perceptions of intrinsic and extrinsic non-monetary rewards are more strongly related to affective commitment than perceptions of extrinsic monetary rewards. 
- Hypothesis 3: Employees' favourable perceptions of intrinsic non-monetary rewards are stronger predictors of affective commitment than extrinsic non-monetary rewards.

\section{Rewards and intrinsic motivation}

Motivation is one of the factors that help employees to perform proficiently (Van Knippenberg, 2000). Research has distinguished between intrinsic and extrinsic motivation (Frey \& Jegen, 2001; Kuvaas, 2006; Melancon, Noble \& Noble, 2010; Pierce, Cameron, Banko \& So, 2003). Intrinsic motivation is understood as the inspiration which emanates from the inherent nature of the job, whilst extrinsic motivation is the incentive to do a job, driven by external factors, for example, pay and bonuses (Amabile, Hill, Hennessey \& Tighe, 1994). This study will specifically focus on intrinsic motivation. Asad and Dainty (2005) found that employees are largely motivated by intrinsic factors and that it is these factors which contribute to their retention.

The relationship between intrinsic rewards and intrinsic motivation is well established in the literature (Asad \& Dainty, 2005; Deci, 1972; Kuvaas, 2006). The more intrinsic satisfaction employees derive from their job, the more intrinsically motivated they are. In contrast, the relationship between extrinsic rewards and intrinsic motivation is contradictory. Frey and Jegen (2001) conducted an econometric study investigating the effect of monetary rewards in the voluntary sector. Participants in this study decreased their volunteering hours when pay was introduced suggesting that monetary rewards decrease intrinsic motivation. This result can be explained using Pierce et al.'s (2003) argumentation that when presented with monetary rewards individuals are more likely to shift their internal interests from performing a task (internal attributions) to external attributions (pay), hence causing a decrease in intrinsic motivation. Thus, it has been suggested that non-monetary rewards should be used instead to boost employees' intrinsic motivation (Deci, 1972).

However, in a paid employment relationship it is possible that EMRs enhance intrinsic motivation rather than to decrease it. According to Wiley (1995) employees may perceive monetary incentives as being a form of recognition and positive feedback for their performance and competence. Deci, Koestner and Ryan (1999) noted that when rewards were given independently of any task engagement, as is the case with an employee's salary, and if these rewards were not expected, such as unanticipated bonuses and monetary rewards had a positive association with intrinsic motivation. Employees were satisfied and more intrinsically motivated to give a high quality performance. However, as long as non-monetary rewards were absent a high motivation did not translate into actual high quality performance. Ryan, Mims, and Koestner (1983), on the other hand, observed that employees' favourable perceptions of monetary rewards were related to an increase in intrinsic motivation when rewards were based on high performance. However, this was only the case if the work environment was supportive. Other studies have also found a positive relationship between a supportive work environment and intrinsic motivation (Brown \& Sheppard, 1997; Skinner \& Belmont, 1993). Brown and Sheppard (1997) suggest that employees will successfully fulfil certain work demands if motivated by the supervisor. When supervisors support employees by exhibiting enthusiasm, providing effective guidance, involvement and rewarding desirable behaviour, subordinates' motivation increases (Skinner \& Belmont, 1993). This claim is also supported by Kirkpatrick and Locke (1996), who suggest that such extrinsic non-monetary rewards improve the inherent aspects of the job by making it more interesting thereby encouraging intrinsic motivation.

Based on the above, the following hypotheses are postulated:

- Hypothesis 4: Employees show higher intrinsic motivation the more favourably they perceive the intrinsic nonmonetary rewards, extrinsic non-monetary rewards and extrinsic monetary rewards provided.

- Hypothesis 5: Employees' favourable perceptions of intrinsic and extrinsic non-monetary rewards are more strongly related to intrinsic motivation than perceptions of extrinsic monetary rewards.

- Hypothesis 6: Employees' favourable perceptions of intrinsic non-monetary rewards are stronger predictors of intrinsic motivation than extrinsic non-monetary rewards.

\section{Research design Research approach}

A correlational research design was employed. The hypotheses were tested using cross-sectional, quantitative data collected via questionnaires.

\section{Research method}

\section{Research participants}

Non-probability sampling was used for sample selection. Questionnaires were distributed electronically and in paper and pencil format to employees in organisations across South Africa using the snowballing technique. Participation was voluntary and 409 participants responded. Seven participants completed less than $75 \%$ of the items on several sub-scales in the questionnaire and their responses were discarded from the dataset. Despite having reverse-coded some questions, acquiescence and centrality response bias was observed throughout the questionnaire for three additional participants. Data of these participants was also deleted. The final sample thus consisted of 399 participants; the majority of which were full-time employees $(81.3 \%)$ and operated at non-management level (69.3\%). On average, participants had been employed in their organisations for 53.7 months $(\mathrm{SD}=77.8)$ and had been reporting to their supervisor for an average of 29.1 months $(\mathrm{SD}=44.2)$. Of the overall sample, 211 participants $(52.9 \%)$ were employed in a large organisation, 118 employees $(29.6 \%)$ were from a small organisation and 51 employees $(12.8 \%)$ worked in a medium-sized organisation whilst the rest $(4.8 \%)$ did not specify the size of their 
organisations. The majority of participants $(72.4 \%)$ indicated the presence of a human resource (HR) department in their organisation. Of the sample, 165 participants were men $(42.1 \%)$ and 226 were women (57.7\%). The remaining $0.3 \%$ did not provide an answer. Participants' ages varied between 20 and 65 years with a mean of $32.8(S D=10.1)$. The majority of participants were between 20 and 39 years old (77.7\%) (see Table 1 for further socio-demographic sample descriptors).

Considering the diversity of the South African population, the sample provides a fair representation of the working population, although it needs to be noted that it is slightly skewed towards younger employees.

\section{Measuring instruments}

The questionnaire consisted of a total of 89 items and was designed to assess employees' perceptions of a variety of leadership and HR practices (such as occupational health practices, training and development) and employees' affective commitment, intrinsic motivation and job satisfaction. It comprised ten subscales and an additional section on participants' demographic and employer details. Responses were provided on a 5-point Likert scale from 1 (strongly disagree) to 5 (strongly agree).

For this research the following subscales are of relevance: affective commitment, intrinsic motivation, job satisfaction (as an indicator of INMRs), reward and recognition (as an indicator of EMRs), and perceived leadership support (as an indicator of ENMRs). A description for each of the scales is provided below.

Affective commitment scale: Allen and Meyer's (1990) 8-item Affective Commitment Scale was used in the study. Allen and Meyer had found adequate reliability for the scale (Cronbach $\alpha=.87$ ), as well as high construct validity, which they established via factor analysis and correlations

TABLE 1: Descriptive statistics of sample.

\begin{tabular}{llcc}
\hline $\begin{array}{l}\text { Socio-demographic } \\
\text { characteristic }\end{array}$ & Description & Number & Percentage \\
\hline Race & Black & 99 & 24.8 \\
& Chinese & 1 & 0.3 \\
& Coloured & 80 & 20.1 \\
& Indian & 16 & 4.0 \\
& White & 170 & 42.6 \\
& Other & 7 & 1.8 \\
& Prefer not to answer & 17 & 4.3 \\
& Unspecified & 9 & 2.3 \\
\hline Home language & Afrikaans & 49 & 12.3 \\
& English & 271 & 67.9 \\
& Xhosa & 17 & 4.3 \\
& Other & 53 & 13.3 \\
& Unspecified & 9 & 2.3 \\
\hline Highest level of & Less than grade 12 & 13 & 3.3 \\
education & Grade 12 or Matric & 165 & 16.3 \\
& First degree or diploma & 171 & 42.9 \\
& Post-graduate & 134 & 33.6 \\
& Unspecified & 16 & 4 \\
\hline
\end{tabular}

$n=399$. with related and unrelated constructs. The wording of three items was slightly adapted and read, 'I feel like part of the family at my organisation', 'I feel emotionally attached to the organisation' and 'I feel a strong sense of belonging to my organisation'. The item 'I think that I could easily become as attached to another organisation as I am to this one' was reverse-coded so that a high score indicates high affective commitment to the organisation.

Intrinsic motivation scale: To assess participants' intrinsic motivation, six items were adapted from Wright's (2001, as cited in Wright \& Rohrbaugh, 2001) motivation subscale. The Cronbach alpha for the scale reported by Wright and Rohrbaugh (2001) was .75 and the authors found good convergent and discriminant validity for the scale when correlating participants' results with other measures. Three items had to be reverse-coded ('It has been hard for me to get very involved in my current job', 'I probably do not work as hard as others who do the same type of work', 'Time seems to drag whilst I am on the job'). A high score on the scale indicates that employees are highly motivated.

Intrinsic non-monetary rewards scale: All five items for this subscale were adapted from a survey instrument developed by Lytle (1994, as cited in Kim, Leong \& Lee, 2005). The reliability as measured by Cronbach's alpha was .80 in Kim et al.'s (2005) research. Although Kim et al. provided no indication of the scale's validity it was chosen because of its high face validity. One item was rephrased as 'I feel satisfied with my present job' for clarity. A high score on the scale indicates that an employee experiences a high level of job satisfaction.

Extrinsic non-monetary rewards scale: The scale comprised of eight items adapted from the 9-item short form of the Survey of Perceived Organisational Support (SPOS) as used by Eisenberger, Fasolo and Davis-LaMastro (1990). Wayne, Shore and Liden (1997) reported a Cronbach alpha coefficient of .93 for the 9-item scale. Wayne et al. conducted a principal component analysis over all items included in their research (comprising different scales) and found that all nine SPOS items loaded on one component. The items reading, 'My supervisor/manager shows very little concern for $\mathrm{me}^{\prime}$ and 'Even if I did my best job possible, my supervisor/manager would fail to notice' were reverse-coded. A high score on the scale indicates that employees are satisfied by the support they receive from their supervisor and thus satisfied with their extrinsic non-monetary rewards.

Extrinsic monetary rewards scale: Six items were adapted from Spector's (1997) 36-item Job Satisfaction Survey to measure employees' perceptions of extrinsic monetary rewards. The Cronbach's alpha coefficient for the overall scale was .91 in Spector's research, demonstrating high internal consistency. Spector was also able to show that the 36-item scale had a satisfactory test-retest reliability of $r=.71$ and good discriminant and convergent validity. The items 'I am satisfied with the benefits I have', 'I feel my efforts are 
TABLE 2: Internal consistencies of scales used in this study.

\begin{tabular}{llll}
\hline Scale & $\begin{array}{l}\text { Cronbach's } \\
\text { alpha } \\
\text { coefficient }\end{array}$ & $\begin{array}{l}\text { Item-total } \\
\text { correlations }\end{array}$ & $\begin{array}{l}\text { Total number } \\
\text { of items on } \\
\text { scale }\end{array}$ \\
\hline Affective commitment & 0.91 & $.61<r<.82$ & 7 \\
Intrinsic motivation & 0.73 & $.39<r<.61$ & 6 \\
Intrinsic non-monetary rewards & 0.94 & $.78<r<.90$ & 5 \\
Extrinsic non-monetary rewards & 0.92 & $.49<r<.82$ & 8 \\
Extrinsic monetary rewards & 0.92 & $.67<r<.86$ & 6 \\
\hline
\end{tabular}

rewarded the way they should be' and 'I feel appreciated by the organisation when I think about what they pay me' had carried a negative connotation and were rephrased. A high score on the scale means that employees are highly satisfied with the rewards offered by the organisation.

\section{Research procedure}

The research project was approved by the University of Cape Town's Faculty of Commerce Ethics in Research Committee. The data was collected by 51 students in a fourth year Honours' programme who had been requested to recruit at least 10 participants each. Students forwarded the link to an electronic questionnaire or paper-and-pencil questionnaires to various employees. A cover letter outlining the purpose of the study and addressing issues of confidentiality and anonymity was attached to the correspondence. Participants could choose to enter into a lucky draw for a R1000 shopping voucher.

\section{Statistical analysis}

All statistical analyses were conducted using the Software Package for the Social Sciences (SPSS), version 18. Reliability (Cronbach alpha and corrected item-total correlations) and validity analyses (principal component analysis) were conducted to establish the appropriateness of the scales. To test the hypotheses, bivariate correlations and multiple regression analysis were used.

\section{Results}

\section{Reliability and validity of scales}

Scales were considered reliable if their Cronbach alpha value reached at least .70 (Nunnally, 1978). Item discrimination was assessed by examining the item-total correlations.

The construct validity of the scales was then explored using principal component analysis. The Kaiser-Meyer-Olkin (KMO) measure and Bartlett's test of sphericity were used to determine the suitability of the data for the procedure. Data was considered suitable if the KMO was greater than .50 and Bartlett's test of sphericity was significant. Only factors with eigenvalue greater than 1 were taken into account (Kaiser, 1970) and factor loadings of greater than .30 were considered significant (Kline, 1986).

An initial reliability analysis for the affective commitment scale revealed an acceptable Cronbach's alpha coefficient of .88 for the eight items. However, the item-total correlation for one item ('I think that I could easily become as attached to another organisation as I am to this one') was non-significant $(r=.14)$ and the item was thus removed from further analyses resulting in a 7-item affective commitment scale. This affective commitment scale, the INMRs scale, ENMRs scale and EMRs scale demonstrated high internal consistency whilst the intrinsic motivation scale revealed an acceptable level of reliability (Table 2).

The KMO and Bartlett's tests demonstrated that the data was appropriate for principal component analysis to be employed. Each scale had only one emerging component with eigenvalue greater than one and all items loaded significantly on this component (Table 3). The expected unidimensionality of each scale was thus confirmed and item responses were averaged into overall scale scores.

\section{Descriptive statistics}

The mean scores indicate that participants had relatively high levels of affective commitment, intrinsic motivation, favourable perceptions of INMRs, ENMRs and EMRs (Table 4).

\section{Results related to hypotheses}

To test Hypotheses 1 and 4, Pearson product moment correlation was used. All correlations were significant at the $1 \%$ level and moderate, except for the correlations between ENMR, as well as EMR, and intrinsic motivation, which were weak (Cohen, 1988) (Table 5). The results thus support Hypotheses 1 and 4: The more employees perceive rewards as favourable the more motivated and committed they are to their employer. In addition, a medium correlation was also observed between affective commitment and intrinsic motivation.

To test the remaining hypotheses, Fisher's r-to-z transformation was used. It was expected that firstly, INMRs and ENMRs would be more strongly related to affective commitment

TABLE 3: Structure of the scales used in the study (determined via principal component analysis).

\begin{tabular}{|c|c|c|c|c|c|c|c|}
\hline \multirow[t]{2}{*}{ Scale } & \multirow[t]{2}{*}{ KMO } & \multicolumn{2}{|c|}{ Bartlett's test of Sphericity } & \multirow{2}{*}{$\begin{array}{l}\text { Eigenvalue: First } \\
\text { component }\end{array}$} & \multirow{2}{*}{$\begin{array}{c}\text { Explained variance } \\
(\%)\end{array}$} & \multirow{2}{*}{$\begin{array}{c}\text { Minimum } \\
\text { component } \\
\text { loading }\end{array}$} & \multirow{2}{*}{$\begin{array}{c}\text { Maximum } \\
\text { component } \\
\text { loading }\end{array}$} \\
\hline & & $\chi^{2}$ & $d f$ & & & & \\
\hline Affective Commitment & 0.90 & $1699.89 * * *$ & 21 & 4.56 & 65.23 & 0.71 & 0.88 \\
\hline Intrinsic Motivation & 0.78 & $488.38^{* * *}$ & 15 & 2.67 & 44.44 & 0.55 & 0.80 \\
\hline INMR & 0.89 & $1766.04^{* * *}$ & 10 & 3.99 & 79.89 & 0.86 & 0.94 \\
\hline ENMR & 0.92 & $2102.15^{* * *}$ & 28 & 5.12 & 64.03 & 0.56 & 0.89 \\
\hline EMR & 0.89 & $1799.61^{* * *}$ & 15 & 4.36 & 72.62 & 0.76 & 0.91 \\
\hline
\end{tabular}

INMR, Intrinsic non-monetary reward; ENMR, Extrinsic non-monetary reward; EMR, Extrinsic monetary reward; KMO, Kaiser-Meyer-Olkin measure; $\chi^{2}$, Chi square; $d f$, degrees of freedom. $* * *, p<0.001$ 
TABLE 4: Descriptive statistics for the variables under investigation.

\begin{tabular}{llll}
\hline Scale name & $\boldsymbol{N}$ & Mean & SD \\
\hline Affective commitment & 399 & 3.39 & 0.97 \\
Intrinsic motivation & 399 & 4.08 & 0.69 \\
Intrinsic non-monetary rewards & 399 & 3.84 & 0.96 \\
Extrinsic non-monetary rewards & 393 & 3.77 & 0.83 \\
Extrinsic monetary rewards & 398 & 2.99 & 1.04 \\
\hline
\end{tabular}

$N$, number of participants; SD, standard deviation.

(hypothesis 2) and intrinsic motivation (hypothesis 5) than EMR. Secondly, it was assumed that INMRs would be more strongly related to affective commitment (hypothesis 3 ) and intrinsic motivation (hypothesis 6) than ENMRs. As expected in hypotheses 2, 3, 5 and 6, INMRs differ significantly from ENMRs and EMRs such that the relationships between INMRs and both, affective and intrinsic motivation are stronger when assuming a 5\% significance level. Contrary to hypotheses 2 and 5 no statistically significant difference was observed between EMRs and ENMRs in the strength of their association with affective commitment and intrinsic motivation (Table 6).

To explore which independent variables best predicted affective commitment and intrinsic motivation further, multiple regression analysis was conducted. The variance inflation factor determined that multi-collinearity amongst the predictor variables was negligible, as VIF $=1.42$ and thus below 5 (Carlsson \& Lundström, 2002).

The overall regression model was significant when using INMRs, ENMRs and EMRs as predictors for affective commitment $\left(F_{3,389}=123.18, p<0.01\right)$. INMRs, ENMRs and EMRs predicted $48.3 \%$ of variability in the criterion variable $(R=.70)$. All rewards categories were significant predictors (significance level 5\%), with INMRs emerging as the strongest predictor (Table 7).

The regression model was also significant when using INMRs, ENMRs and EMRs to predict intrinsic motivation $\left(F_{3,389}=48.54, p<0.05\right)$. The regression model accounted for
$26.7 \%$ of variance in intrinsic motivation scores $(R=.52)$. The standardised beta coefficients (Table 8) show that EMRs are no longer a significant predictor of intrinsic motivation $(p=.16)$ after controlling for INMRs and ENMRs.

These results thus indicate partial support for Hypotheses 2 and 5. As expected, favourable perceptions of INMRs are more strongly associated with the dependent variables than EMRs. However, contrary to assumptions, there was no difference in the strength of association between the two types of extrinsic rewards and the two dependent variables. The multiple regression analysis provided a slightly more differentiated picture: although the bivariate correlations between extrinsic EMRs and ENMRs with intrinsic motivation indicated a similar strength only ENMRs significantly predicted intrinsic motivation. This indicates that when considering intrinsic and the two types of extrinsic rewards together, monetary rewards do not explain unique variance in intrinsic motivation. Thus, employee satisfaction with ENMRs seem to be more important than satisfaction with monetary rewards in predicting staff motivation.

\section{Discussion}

The aim of this study was to assess the relationship between employees' favourable perceptions of rewards, affective commitment and intrinsic motivation. The findings by and large support the proposed hypotheses. The following three main findings were revealed:

- The more satisfied employees are with either of the reward types under investigation, the more affectively committed and intrinsically motivated they are.

- This relationship is stronger for intrinsic than for extrinsic rewards.

- Satisfaction with monetary rewards does not predict intrinsic motivation when considered in combination with ENMRs and INMRs satisfaction.

These results highlight that all types of rewards are relevant in building a motivated and committed workforce. However,

TABLE 5: Inter-correlation matrix for the variables under investigation.

\begin{tabular}{|c|c|c|c|c|c|c|c|c|}
\hline \multirow[t]{2}{*}{$r$} & \multicolumn{2}{|c|}{ Intrinsic motivation } & \multicolumn{2}{|c|}{ INMR } & \multicolumn{2}{|c|}{ ENMR } & \multicolumn{2}{|c|}{ EMR } \\
\hline & $r$ & $n$ & $r$ & $n$ & $r$ & $n$ & $r$ & $n$ \\
\hline Affective commitment & $.40 * *$ & 399 & $.65^{* *}$ & 399 & $.51 * *$ & 393 & $.50 * *$ & 398 \\
\hline Intrinsic motivation & - & - & $.51^{* *}$ & 399 & $.32 * *$ & 393 & $.22^{* *}$ & 398 \\
\hline INMR & - & - & - & - & $.48^{* *}$ & 393 & $.47^{* *}$ & 398 \\
\hline ENMR & - & - & - & - & - & - & $.52 * *$ & 393 \\
\hline
\end{tabular}

INMR, Intrinsic non-monetary rewards; ENMR, Extrinsic non-monetary rewards; $r$, Pearson product-moment correlation; $n$, number of participants; EMR, Extrinsic monetary reward. ${ }^{* *}, p<0.01$

TABLE 6: Pearson product moment correlation coefficients $(r)$ and the difference (expressed as $z$-values) between $z$-transformed correlation coefficients for the different types of rewards with affective commitment and intrinsic motivation.

\begin{tabular}{|c|c|c|c|c|c|c|c|}
\hline Variable & Statistical procedure & INMR & ENMR & INMR & EMR & EMR & ENMR \\
\hline \multirow[t]{2}{*}{ Affective commitment } & $r$ & 0.65 & 0.51 & 0.65 & 0.5 & 0.49 & 0.51 \\
\hline & Difference: $z$-transformed $r^{\prime}$ s & $3.01 *$ & - & $3.32 *$ & - & 0.30 & - \\
\hline \multirow[t]{2}{*}{ Intrinsic motivation } & $r$ & 0.51 & 0.32 & 0.51 & 0.22 & 0.22 & 0.32 \\
\hline & Difference: $z$-transformed $r^{\prime}$ s & $3.19 *$ & - & $4.69 *$ & - & 1.48 & - \\
\hline
\end{tabular}

$r$, Pearson product-moment correlation; INMR, Intrinsic non-monetary rewards; ENMR, Extrinsic non-monetary rewards; EMR, Extrinsic monetary rewards.

$*, p<.05$ 
TABLE 7: Standardised beta coefficients $(\beta)$ of predictor variables of affective commitment.

\begin{tabular}{ll}
\hline Predictor variable & $\boldsymbol{\beta}$ \\
\hline Intrinsic non-monetary rewards & $.48^{*}$ \\
Extrinsic non-monetary rewards & $.22^{*}$ \\
Extrinsic monetary rewards & $.16^{*}$ \\
\hline
\end{tabular}

Extrinsic monetary rewards

$*, p<0.05$

TABLE 8: Standardised beta coefficiencts $(\beta)$ of predictor variables of intrinsic motivation.

\begin{tabular}{ll}
\hline Predictor variable & $\boldsymbol{\beta}$ \\
\hline Intrinsic non-monetary rewards & $.49^{*}$ \\
Extrinsic non-monetary rewards & $.12^{*}$ \\
Extrinsic monetary rewards & -0.75 \\
\hline
\end{tabular}

$*, p<0.05$

the three types of rewards investigated in this study have different relative importance. The satisfaction employees derive from the intrinsic characteristics of their job, such as responsibility and tasks appeal, is more important for intrinsic motivation and emotional attachment to the organisation than external rewards in the form of monetary benefits or supervisory support. These findings are in agreement with the outcomes of past research. Melancon et al. (2010) found that intrinsic and extrinsic non-monetary as well as monetary rewards have a positive relationship with affective commitment, but intrinsic rewards, such as role clarity and autonomy, are more strongly associated with affective commitment. Similarly, the current results confirm the findings of Deci (1972), Deci et al. (1999) and Brown and Sheppard (1997) with regards to intrinsic motivation. Whilst all three types of rewards are associated with intrinsic motivation, non-monetary rewards are more strongly related to the latter.

The current research provides interesting findings for extrinsic monetary rewards in that, in conjunction with intrinsic and extrinsic non-monetary rewards, monetary rewards predict employees' affective commitment but not their intrinsic motivation. This can be explained using the norm of reciprocity and perceptions of fairness and equity. When organisations show commitment towards employees and provide substantively fair bonuses and salary packages that are gratifying, employees reciprocate their loyalty in the form of affective commitment (Burke, 2002). However, the same does not apply to intrinsic motivation because, being extrinsic in nature, monetary rewards are more likely to lead to extrinsic motivation.

The purpose of this research was to explore to what extent types of rewards are related to employee attitudes amongst employees in South African workplaces. This was deemed important because internationally the relationships between rewards and employee attitudes have been extensively investigated but research conducted in the South African context has been scarce. The results of this study demonstrated that by and large the relationships between different types of rewards, and affective commitment and intrinsic motivation were similar to those found in other societies. This is important, as this finding contradicts Huang and Van de Vliert's (2003) view that employees in poorer countries are satisfied with the basics of the employment relationship, which in South Africa include fair monetary rewards. Huang and Van de Vliert argued that employees in economically developed countries, on the other hand, tend to take survival for granted. In those countries values attached to non-monetary rewards such as satisfaction and quality of work-life are perceived as more important than monetary rewards. Although South Africa is considered an advanced emerging economy (FTSE Group, 2011), the results of this study are more in line with what Huang and Van de Vliert would expect to emerge in well-developed countries. This could be explained with the particular characteristics of the sample used in this study. The majority of participants were relatively highly educated employees who had at least obtained a first diploma or degree. This indicates that participants in this study were individuals living above the poverty line and thus in circumstances similar to those in economically developed countries. Had the sample consisted of a majority of low-skilled or unskilled employees who are representative of the poorer local population, the results might have been different. However, organisations are particular concerned about retaining their highly skilled workforce, as it is more difficult to replace these than a lesser skilled employee. It is thus exactly the demographic group represented in this study that is of most interest to organisations. South African employers thus need to take cognisance of the fact that monetary rewards seem to have less relevance in creating and maintaining a motivated and committed workforce in comparison to non-monetary and in particular intrinsic rewards. This is important, as previous research has established a link between affective commitment and motivation and employees' intention to quit in that less committed and motivated employees are more likely to leave the employment relationship (Mowday, 1998; Ramlall, 2004). Satisfying employees' needs and expectations are thus key aspects of retention; that is, organisations that seek to retain their highly skilled workforce need to provide employees with benefits other than those of a monetary nature. The results have shown that for highly educated employees in South Africa non-monetary, particularly intrinsic rewards contribute more to creating commitment and intrinsic motivation. Employers in South Africa should thus place particular emphasis on designing jobs in such a way that employees find them intrinsically rewarding, for example, by ensuring employees are exposed to a variety of tasks and allowing them to challenge their potential. By strategically managing rewards which are more strongly associated with affective commitment and intrinsic motivation, employers can capitalise on the benefits of a committed workforce.

\section{Limitations and directions for future research}

Despite the significance of its findings this study carries two limitations. Firstly, the design followed a correlational approach, meaning that cause and effect between the variables could not be established. It is not clear whether committed and motivated employees perceive their rewards 
more favourably or whether the favourable perception of rewards leads to an increased commitment and motivation. In interpreting the results it was assumed that the way in which rewards are perceived co-creates commitment and motivation. Future research should seek to substantiate this inferred causal effect between the variables empirically.

Secondly, other potentially relevant variables were not taken into account. Tang, Kim and Tang (2002), for example, suggest that perceptions of rewards may be affected by personality characteristics. For instance, Type A employees are characterised by an extreme sense of competitiveness, aggressiveness, ambition and tend to value monetary rewards more than the non-monetary rewards. Future research might thus want to examine whether personality variables affect the relationship between rewards and employees' intrinsic motivation and affective commitment.

\section{Conclusion}

The study was conducted to investigate how favourable perceptions of rewards are related to intrinsic motivation and affective commitment in South Africa. A rewards taxonomy differentiated between intrinsic non-monetary, extrinsic non-monetary and extrinsic monetary rewards. Despite its limitations, this study provides significant insights into understanding the contribution of different types of rewards to employees' organisational attitudes in South Africa. In line with past international literature, this study suggests that it is important for South African organisations to emphasise the value of intrinsic rewards as part of their rewards management strategies. By effectively managing their rewards strategies, organisations are likely to attract, retain and capitalise on the benefits of a loyal and high calibre workforce.

\section{Acknowledgements Competing interests}

The authors declare that they have no financial or personal relationship(s) which may have inappropriately influenced them in writing this paper.

\section{Authors' contributions}

The study was conducted by A.N. (University of Cape Town) as part of her Honours in Organisational Psychology research project at the University of Cape Town in 2011. I.M. (University of Cape Town) was A.N.'s (University of Cape Town) supervisor and edited the work for publication.

\section{References}

Adeyemo, D.A., \& Aremu, A.O. (1999). Career commitment among secondary school teachers in Oyo state, Nigeria: The Role of biographical mediators. Nigerian Journal of Applied Psychology, 5(2), 184-194.

Allen, N.P., \& Meyer, J.P. (1990). The measurement and antecedents of affective, continuance and normative commitment to the organisation. Journal of Occupational Psychology, 63, 1-18. http://dx.doi.org/10.1111/j.2044-8325.1990. tb00506.x

Amabile, T.M., Hill, K.G., Hennessey, B.A., \& Tighe, E.M. (1994). The work preference inventory: Assessing intrinsic and extrinsic motivational orientations. Journal of Personality and Social Psychology, 66(5), 950-967. http://dx.doi. org/10.1037/0022-3514.66.5.950, PMid:8014837
Amabile, T.M., Schatzel, E.A., Moneta, G.B., \& Kramer, S.J. (2004). Leader behaviors and the work environment for creativity: Perceived leader support. The Leadership Quarterly, 15, 5-32. http://dx.doi.org/10.1016/j.leaqua.2003.12.003

Amabile, T.M., Hill, K.G., Hennessey, B.A., \& Tighe, E. (1994). The work preference inventory: Assessing intrinsic and extrinsic motivational orientations. Journal of Personality and Social Psychology, 66, 950-967. http://dx.doi.org/10.1037/00223514.66.5.950, PMid:8014837

Asad, S., \& Dainty, A.R.J. (2005). Job motivational factors from disparate occupational groups within the UK construction sector: a comparative analysis. Journal of Construction Research, 6(2), 223-236. http://dx.doi.org/10.1142/ S1609945105000341

Bratton, J., \& Gold, J. (2007). Human Resource Management: Theory and Practice. (4th edn.). New York: Palgrave Macmillan.

Brown, J., \& Sheppard, B. (1997, August). Teacher librarians in learning organizations. Paper presented at the Annual Conference of The International Association of School Librarianship, Canada. Retrieved September 22, 2011, from http://eric ed.gov/PDFS/ED412959.pdf

Buitendach, J.H., \& De Witte, H. (2005). Job insecurity, extrinsic and intrinsic job satisfaction and affective organisational commitment of maintenance workers in a parastatal. South African Journal of Business Management, 36(2), 27-37.

Burke, W.W. (2002). Organizational Change: Theory and Practice. Sage: Thousand Oaks.

Carlsson, F., \& Lundström, S. (2002). Economic Freedom and Growth: Decomposing the Effects. Public Choice, 112(3), 335-344. http://dx.doi. org/10.1023/A:1019968525415

Chen, C.C., Ford, C.M., \& Farris, G.F. (1999). Do rewards benefit the organization? The effects of reward types and the perceptions of diverse R\&D professionals. Transactions on Engineering Management, 46(1), 47-55. http://dx.doi. org/10.1109/17.740037

CNN Money. (2011). 100 Best Companies to Work for. Retrieved September 22, 2011 from http://money.cnn.com/magazines/fortune/bestcompanies/2011/full_list

Cohen, J. (1988). Statistical Power Analysis for the Behavioral Sciences. Hillsdale, New Jersey: Erlbaum.

Deci, E.L. (1972). The effects of contingent and non-contingent rewards and controls on intrinsic motivation. Organizational Behaviour and Human Performance, 8 217-229. http://dx.doi.org/10.1016/0030-5073(72)90047-5

Deci, E.L., Koestner, R., \& Ryan, R. (1999). A meta-analytic review of experiments examining the effects of extrinsic rewards on intrinsic motivation. Psychological Bulletin, 125(6), 627-626. http://dx.doi.org/10.1037/0033-2909.125.6.627 Bulletin, $125(6)$
PMid:10589297

Eby, L.T., Freeman, D.M., Rush, M.C., \& Lance, C.E. (1999). Motivational bases of affective organizational commitment: A partial test of an integrative theoretical model. Journal of Occupational and Organizational Psychology, 72(4), 463-483. http://dx.doi.org/10.1348/096317999166798

Eisenberger, R., Fasolo, P., \& Davis-LaMastro, V. (1990). Perceived organizational support and employee diligence, commitment, and innovation. Journal of Applied Psychology, 75(1), 51-59. http://dx.doi.org/10.1037/0021-9010.75.1.51

Eisenberger, R., Stinglhamber, F., Vandenberghe, C., Sucharski, I.L., \& Rhoades, L. (2002). Perceived supervisor support: Contributions to perceived organizational support and employee retention. Journal of Applied Psychology, 87(3), 565-573. http://dx.doi.org/10.1037/0021-9010.87.3.565, PMid:12090614

Frey, B.S., \& Jegen, R. (2001). Motivation crowding theory: A survey of empirical evidence. Journal of Economic Surveys, 15(5), 589-611. http://dx.doi. org/10.1111/1467-6419.00150

FTSE (2011). FTSE Global Equity Index Series Country Classification: September 2011 update. Retrieved September 22, 2011, from http://www.ftse.com/ Indices/Country_Classification/Downloads/Sept\%202011/Sept_2011_Country_ Classification_Update.pdf

Gagnon, M.A., \& Michael, J.H. (2004). Outcomes of perceived supervisor support for wood production employees. Forest Products Journal, 54(12), 172-177.

Greenberg, J. (2011). Behavior in organisations. (10th edn.). Essex: Pearson Education Limited.

Herzberg, F. (1959). The Motivation to Work. New York: John Wiley \& Sons.

Huang, X., \& Van de Vliert, E. (2003). Where intrinsic job satisfaction fails to work: National moderators of intrinsic motivation. Journal of Organizational Behavior 24(2), 159-179. http://dx.doi.org/10.1002/job.186

Kallerberg, A.L. (1977). Work values and job rewards: A theory of job satisfaction. American Social Review, 42, 124-143. http://dx.doi.org/10.2307/2117735

Kaiser, H.F. (1970). A second-generation little giffy. Psychometrika, 35, 401-415. http://dx.doi.org/10.1007/BF02291817

Katz, R., \& Van Maanan, J. (1977). The loci of work satisfaction: Job interaction and policy. Human Relations, 30, 469-486. http://dx.doi.org/10.1177/001872677703000505

Kim, W.G., Leong, J.K., \& Lee, Y.K. (2005). Effect of service orientation on job satisfaction, organizational commitment, and intention of leaving in a casual dining chain restaurant. International Journal of Hospitality Management, 24 171-193. http://dx.doi.org/10.1016/j.ijhm.2004.05.004

Kinnear, L., \& Sutherland, M. (2001). Money is fine, but what is the bottom-line. Journal of the South African Institute of People Management, 19(1), 15-18.

Kirkpatrick, S.A., \& Locke, E.A. (1996). Direct and indirect effects of three core charismatic leadership components on performance and attitudes. Journal of Applied Psychology, 81, 36-51. http://dx.doi.org/10.1037/0021-9010.81.1.36

Kline, P. (1986). Handbook of Test Construction: Introduction to Psychometric Design. Methuen: London. 
Kuvaas, B. (2006). Work performance, affective commitment, and work motivation The roles of pay administration and pay level. Journal of Organizational Behaviour, 27, 365-385. http://dx.doi.org/10.1002/job.377

Malhotra, N., Budhwar, P., \& Prowse, P. (2007). Linking rewards to commitment An empirical investigation of four UK call centres. International Journal of Human Resource Management, 18(12), 2095-2017. http://dx.doi. of Human Resource Manageme

Melancon, J.P., Noble, S.M., \& Noble, C.H. (2010). Managing rewards to enhance relational worth. Journal of the Academy Marketing Science, 39(3), 341-362. http://dx.doi.org/10.1007/s11747-010-0206-5

Meyer, J.P., \& Allen, N.J. (1991). A three component conceptualization of organizational commitment. Human Resource Management Review, 1, 61-89. http://dx.doi. org/10.1016/1053-4822(91)90011-Z

Meyer, J.P., \& Allen, N.J. (1997). Commitment in the workplace: Theory, research and application. Thousand Oaks, CA: Sage.

Mottaz, C.J. (1985). The relative importance of intrinsic and extrinsic rewards as determinants of work satisfaction. The Sociological Quarterly, 26(3), 365-385. http://dx.doi.org/10.1111/j.1533-8525.1985.tb00233.x

Mowday, R.T. (1998). Reflections on the study and relevance of organizational commitment. Human resource Management review, 8(4), 387-401. http://dx.doi. org/10.1016/S1053-4822(99)00006-6

Nunnally, J.C. (1978). Psychometric Theory. (2nd edn.). McGraw-Hill: New York.

O'Reilly, C.A., \& Caldwell, D.F. (1980). Job choice: The impact of intrinsic and extrinsic factors on subsequent satisfaction and commitment. Journal of Applied Psychology, 65(5), 559-565. http://dx.doi.org/10.1037/0021-9010.65.5.559

Perkins, D.N. (1988). The possibility of invention. In R.J. Sternberg (Ed.), The Nature of Creativity, (n.p.). Cambridge University Press.

Pierce, W.D., Cameron, J., Banko, K.M., \& So, S. (2003). Positive effects of rewards and performance standards on intrinsic motivation. The Psychological Record, 53, and perform.

Porter, L.W., \& Lawler, E.E. (1968). Managerial Attitudes and Performance. Homewood, IL: Dorsey Press.

Ramlall, S. (2004). Review of employee motivation theories and their implications for employee retention within organisations. Journal of American Academy of Business, 5(1), 52-63.

Randall, D.M., \& O'Driscoll, M.P. (1997). Affective versus calculative commitment: Human resource implications. The Journal of Social Psychology, 137(5), 606-617. http://dx.doi.org/10.1080/00224549709595482

Rupert, N. (2011, June 10). Google staff highest paid workers in technology sector Guardian.Co.Uk. Retrieved September 22, 2011, from http://www.guardian. co.uk/business/2011/jun/10/technology-google
Ryan, R.M., Mims, V., \& Koestner, R. (1983). Relation of reward contingency and interpersonal context to intrinsic motivation: A review and test using cognitive evaluation theory. Journal of Personality and Social Psychology, 45, 736-750. http://dx.doi.org/10.1037/0022-3514.45.4.736

Selden, S.C., \& Brewer, G.A. (2000). Work motivation in the senior executive service: Testing the high performance cycle theory. Journal of Public Administration Research and Theory, 3, 531-550. http://dx.doi.org/10.1093/oxfordjournals. jpart.a024280

Skinner, E.A., \& Belmont, M.J. (1993). Motivation in the classroom: Reciprocal effects of teacher behavior and student engagement across the school year. Journa of Educational Psychology, 85(4), 571-581. http://dx.doi.org/10.1037/0022 0663.85.4.571

Spector, P. (1997). Job Satisfaction: Application, Assessment, Causes and Consequences. California: Sage.

Squires, G. (2001). Management as a professional discipline. Journal of Management Studies, 38(4), 473-487. http://dx.doi.org/10.1111/1467-6486.00245

Tang, T.L., Kim, J.K., \& Tang, T.L. (2002). Endorsement of the money ethic, income and life satisfaction: A comparison of full-time employees, part-time employees and non-employed university students. Journal of Managerial Psychology, 17(6), 442-467. http://dx.doi.org/10.1108/02683940210439388

The Google Culture. (2011). Google Corporate Information. Retrieved September 22 , 2011, from http://www.google.com/about/corporate/company/culture.html

Ulrich, D. (1997). Human Resource Champions. Boston, MA: Harvard Business School Press.

Van Knippenberg, D. (2000). Work motivation and performance: A social identity perspective. International Association for Applied Psychology, 49(3), 357-371. http://dx.doi.org/10.1111/1464-0597.00020

Wayne, S., Shore, L., \& Liden, R. (1997). Organizational support and leader-member exchange: A social exchange perspective. The Academy of Management Journal, 40, 82-111. http://dx.doi.org/10.2307/257021

Weatherly, R.L. (2002). Effects of external rewards on internal motivation and job satisfaction. Master's thesis. Retrieved n.d., from http://etd.lib.ttu.edu/theses/ available/etd-0731200831295017084509/unrestricted/31295017084509.pdf

Wiley, C. (1995). What motivates employees according to over 40 years of motivation surveys. International Journal of Manpower, 18(3), 263-280. http://dx.doi. org/10.1108/01437729710169373

Williams, M.L., Brower, H.H., Ford, L.R., Williams, L.J., \& Carraher, S. (2008). A comprehensive model and measure of compensation satisfaction. Journa of Occupational and Organizational Psychology, 81, 639-668. http://dx.doi. org/10.1348/096317907X248851

Wright, B.E., \& Rohrbaugh, J. (2001, October). Antecedents and correlates of organizational commitment: Testing the contributions of a four-tier conceptual model. Paper presented at the 6th National Public Management Research Conference. Retrieved n.d., from http:// www.spea.indiana.edu/npmrc6/ Rohrbaugh.doc 